Michaela Harbeck

Staatssammlung für Anthropologie

und Paläoanatomie München

M.Harbeck@1rz.uni-muenchen.de

Gisela Grupe

Staatssammlung für Anthropologie

und Paläoanatomie München,

Ludwig-Maximilians-Universität München

G.Grupe@lrz.uni-muenchen.de
Ingrid Wiechmann Ludwig-Maximilians-Universität München I.Wiechmann@1rz.uni-muenchen.de

UDK 902.2:616-091.5"653"(430)

616.981.45-091.5:577.21(430)

Original research article

Received: September 08, 2010

Accepted: October 03, 2010

\title{
MOLEKULARGENETISCHE DETEKTION VON KRANKHEITSERREGERN AN ARCHÄOLOGISCHEM SKELETTMATERIAL AM BEISPIEL VON YERSINIA PESTIS
}

\section{ZUSAMMENFASSUNG}

Pandemien, wie die Pest, prägten den Verlauf der Menschheitsgeschichte. Allerdings wird bis heute der Auslöser dieser Pandemien kontrovers diskutiert. So ist umstritten, ob das Bakterium Yersinia pestis, der Erreger der Pest, für die sogenannte Justinianische Pest oder den Schwarzen Tod verantwortlich war. In den hier vorgestellten Studien wurden sowohl Individuen von einer frühmittelalterlichen Grablege (Aschheim, Bayern, Deutschland) als auch aus einem mittelalterlichen Massengrab (Manching-Pichl, Bayern, Deutschland) untersucht, bei denen aufgrund der Fundumstände die Vermutung bestand, dass es sich um mögliche Pestopfer gehandelt haben könnte. Um dies zu überprüfen, wurde versucht, Yersinia-pestis-spezifische DNA-Fragmente wiederzugewinnen und zu analysieren. Genau wie die DNA des Individuums selbst, kann sich die DNA des Bakteriums, welches sich zum Zeitpunkt des Todes in der Blutbahn des Opfers befunden hat, in den skeletalen Überresten seines Opfers erhalten. Der Nachweis Y. pestis spezifischer DNA gelang bei Individuen beider Fundorte. Hierdurch ist zum einen die Todesursache der entsprechenden Individuen eindeutig bestimmt, zum anderen ist die Erkrankung für die jeweilige Bevölkerung nachgewiesen. Im Falle der Pestdetektion bei Individuen des Gräberfeldes Aschheim-Bajuwarenring handelt es sich dabei um den bis heute einzigen bekannten Hinweis, dass sich die Justinianische Pest auch nördlich der Alpen ausgebreitet hat. So bestätigt die Detektion von Y. pestis-DNA in Skelettmaterial aus den Zeiten der Justinianischen Pest und des Schwarzen Todes nicht nur, dass es sich bei diesen Pandemien höchstwahrscheinlich um die Pest gehandelt hat, sondern hilft auch, die Verbreitung der frühmittelalterlichen Pandemie zu bestimmen.

Key words: Pest, Yersinia pestis, alte DNA, molekulargenetische Paläopathologie, Paläomikrobiologie, Schwarzer Tod

\section{EINLEITUNG:}

Infektionskrankheiten führen heute noch die Liste der Todesursachen weltweit an (WHO Statistik). Diese Erkrankungen werden häufig durch bakterielle Erreger verursacht, die schon seit Jahrhunderten existieren: Ausbrüche von Pest,
Typhus oder Cholera prägten in vorantibiotischen Zeiten den Verlauf der Menschheitsgeschichte (Übersichten bei Vasold 2008).

Aufgrund der nur ungenauen Beschreibung des Krankheitsbildes in historischen Quellen ist allerdings oft unklar, welches Bakterium der Auslöser für eine bestimmte historisch überlieferte 
Epidemie war. Weiterhin ist die Feststellung eines Seuchengeschehens in einzelnen historischen Populationen mit großen Schwierigkeiten verbunden, da die historische Quellenlage häufig nicht vollständig ist. Problematisch sind aber insbesondere Zeiträume oder Regionen für die historische Überlieferungen fehlen. Im archäologischen Befund können zwar z. B. Massengräber Hinweise auf Epidemien geben, deren Ursache kann allerdings nicht genauer eingegrenzt werden.

Einen weiteren und den einzigen direkten Zugang zur Aufklärung historischer Epidemien stellen skeletale Überreste von Lebewesen dar. Doch die wenigsten Infektionskrankheiten lassen sich morphologisch detektieren, so hinterlassen z. B. Pest oder Typhus keine sichtbaren Spuren am Skelett. Allerdings kann sich die DNA bakterieller Erreger von Infektionskrankheiten im Knochenoder Zahnmaterial ihrer Opfer erhalten haben. Die Analyse dieser ,alten DNA“ (aDNA) aus historischen Skelettfunden bietet somit einen neuen Zugang zur Erforschung der Epidemiologie von Infektionskrankheiten in vergangenen Zeiten und historischen Bevölkerungen. Der Nachweis von Erkrankungen mittels Detektion von Erreger-DNA aus historischem Knochenmaterial (molekulargenetische Paläopathologie, Paläomikrobiologie) ist ein relativ junges und sich aktuell stark entwikkelndes forschungsgebiet. Die aktuelle Datenlage zeigt, dass Wirt-assoziierte mikrobielle DNA für bis zu 20000 Jahren erhalten bleiben kann (Übersicht bei Drancourt and Raoult 2005: 23-35). Bis heute konnten so zum Beispiel folgende Infektionskrankheiten an historischem humanen Skelettmaterial molekulargenetisch nachgewiesen werden: Tuberkulose (Übersicht bei Donoghue et al. 2004: 584-592, Stone et al. 2009: 66-94), Lepra (z. B. Donoghue et al. 2001: 177-182), Syphilis (z. B. Kolman et al. 1999: 2060-2063), Malaria (Sallares and Gomzi 2001: 195-213) und Typhus (Papagrigorakis et al. 2006: 206-214).

In dem vorliegenden Manuskript werden Ergebnisse aus vorherigen Studien zur Pest aus unserer Arbeitsgruppe (Garrelt and Wiechmann 2003: 247-254, Wiechmann and Grupe 2005: 4855, Wiechmann et al. 2010: 1806) zusammengefasst, um die Möglichkeit des Nachweises darzustellen. Die Implikationen der Ergebnisse dieser Studien hinsichtlich der Erforschung der Pest werden anschließend unter Betrachtung weiterer molekulargenetischer Studien diskutiert.

\section{Der Pesterreger, seine Ökologie und das induzierte Krankheitsbild}

Verursacht wird die Infektionskrankheit Pest durch das Bakterium Yersinia pestis, einem gramnegativen, fakultativ anaerobem Stäbchenbakterium, das zur Familie der Enterobacteriaceae gehört.

Die Pest ist eine Zoonose, die hauptsächlich bei wild lebenden Nagetieren auch heute noch in den USA, Teilen Südamerikas, Südafrikas, Südostasiens und Madagaskars vorkommt (Gage and Kosoy 2005: 507). Yersinia pestis existiert in diesen Reservoirs in sogenannten enzootischen Zyklen, bei denen die Übertragung zwischen den Tieren, die teilresistent gegen die Erkrankung sind, durch Flöhe vermittelt wird. Gelegentlich kommt es zu der Übertragung auf einen gegen die Krankheit empfindlicheren Wirt außerhalb dieses enzootischen Zyklus, was zu einer hohen Sterblichkeit unten diesen führt (epizootischer Zyklus) (Übersicht bei Gage und Kosoy 2005: 507-509).

Pestepidemien in menschlichen Populationen treten in der Regel dann auf, wenn der Pesterreger in Rattenpopulationen einbricht, die nahe dem Menschen leben (insbesondere im Falle der Hausratte Rattus rattus) Die infizierten Rattenflöhe (Xenopsylla cheopis) befallen nach dem Massensterben ihres Primärwirtes - der Ratte - auch den Menschen (Klassischer Pestzyklus).

Bei einer Erkrankung des Menschen werden mehrere Formen der Pest unterschieden (nach Poland and Dennis 1999: 43-54). Die klassische 
Erkrankung beim Menschen ist die Beulenpest, die durch den Stich eines infizierten Flohs ausgelöst wird. Nach einer Inkubationszeit von zwei bis sechs Tagen werden die namensgebenden Schwellungen der Lymphknoten (je nach Einstichstelle im Leisten-, Achsel- oder Halsbereich) sichtbar und weitere Symptome wie Fieber, Mattheit, Bewusstseinsverwirrung etc. zeigen sich. Neben dieser Hauptform tritt noch die Pestsepsis als Infektion des Blutes, sowie die Lungenpest auf. Letztere kann sich durch Streuung des Erregers in die Lungen aus der Beulenpest entwickeln (sekundäre Lungenpest). Bei dieser Form kann dann das Pestbakterium durch Tröpfcheninfektion auch von Mensch zu Mensch übertragen werden (primäre Lungenpest). Generell variiert die Sterblichkeitsrate bei einer Pesterkrankung von 30\% bis $100 \%$ (letztere bei der primären Lungenpest, Stenseth et al. 2008: 0011).

\section{Historische Pestepidemien}

Die Pest und damit Yersinia pestis als ihr Verursacher wird mit mehreren historisch bekannten Pandemien in der Geschichte der Menschheit in Verbindung gebracht. Als einzig gesicherte Pestpandemie kann allerdings nur der jüngste weltweite Ausbruch der Pest im neunzehnten Jahrhundert gelten, da erst hier der Erreger Yersinia pestis durch Alexandre Yersin (Yersin 1894: 662-557) entdeckt und somit zweifelsfrei als Verursacher nachgewiesen werden konnte. Aufgrund überlieferter Beschreibungen von Pestepidemien der Vergangenheit, also aus der Zeit vor 1894, kann man lediglich von der Wahrscheinlichkeit ausgehen, dass diese durch den Erreger Yersinia pestis verursacht wurden.

Aus der Seuchenbeschreibung in der Antike lassen sich kaum sichere Diagnosen ableiten. Neben der „Pest“" von Athen im Jahre 430 v. Chr., bei der Perikles stirbt, sind mehrere Seuchen aus der Zeit des römischen Reiches bekannt. Die schwerste Epidemie war die der Antoninischen „Pest“", die das gesamte römische Reich zwischen 169 und 194 erfasste und zum Tod von Marcus Aurelius führte. Auch zwischen 254 und 266 wurde das Empire wiederum von einer Seuche getroffen, die ähnliche Ausmaße hatte (Übersicht bei Retief and Cilliers 2000: 267-272).

Die erste Pestpandemie, die weite Teile Europas betraf und als deren wahrscheinlichster Verursacher Y. pestis gilt, ist allerdings die sogenannte Justinianische Pest, die zum ersten Mal zur Zeit des oströmischen Kaisers Justinian I (527-565) ausbrach. Die „Pest des Justinian“ i. e. S. herrschte in den Jahren 541 - 544. Auch die durch sie verursachten (die Pest blieb endemisch erhalten) nachfolgenden kleineren Epidemien werden zu der Justinianischen Pest in Abgrenzung zur mittelalterlichen Pest (Schwarzer Tod) gezählt. Der geographische Ursprung der Justinianischen Pest ist nicht eindeutig, auch weil er von den historischen Quellen unterschiedlich benannt wird (Diskussion bei Sarris 2002: 169-182). Viele Schreiber dokumentierten diese Periode, die drei Hauptquellen stammen jedoch von John von Ephesus, Evagrius Scholasticus und im speziellen Procopius, der in seiner Geschichte des Krieges (publiziert 550 nach Chr.) die Symptome und Auswirkungen beschreibt. Procopius gibt einen Ursprung der Pest in Ägypten, nahe Pelusium, an während Evagrius als Ursprung Axum (Äthiopien) angibt. Populationsgenetische Analysen rezenter Pesterreger legen allerdings einen Ursprung in Asien nahe (Morelli et al. 2010: 1143). Von diesem Ursprung verbreitete sich die Pest über die römische Welt, wobei ihre Verbreitung von Handelswegen und Truppenbewegungen durch Justinian gefördert wurde. Sie trat nach den historischen Quellen in jedem Fall in Ägypten im Jahr 541 auf, um 543 erreichte sie Italien und im gleichen Jahr Syrien und Palästina, von wo sie sich nach Persien ausbreitete. Gregor von Tours beschreibt wie die Bewohner von Clermont-Ferrand in Gallien vom heiligen St. Gallen im Jahr 543 vor der Pest gerettet wurden. 
Die Opfer dieser Pandemie können nur geschätzt werden. Procopius gab an, dass 10000 Menschen täglich in Konstantinopel starben (Übersicht bei Little 2007: 1-32). Sicher ist, dass der Einfluss dieser Pandemie auf die römische Welt beträchtlich gewesen sein muss. Nach Bergdolt (2006) beeinflusste nie wieder eine Seuche so umfassend und nachhaltig die politische und kulturelle Entwicklung einer Epoche wie die Pest zur Zeit der Völkerwanderung. Inwieweit sie das östliche Imperium schwächte und zu dessen Untergang beitrug, wird diskutiert (Sarris 2002: 169-182). Während der Kaiser die Pest 544 für das byzantinische Reich offiziell für erloschen erklärte, flackerte sie 577 wieder auf und blieb etwa 200 Jahre endemisch (Bergdolt 2006).

Die am besten greifbare historische Pandemie ist jedoch die des Schwarzen Todes im Mittelalter (1347-1353). Diese Pandemie nahm, den geschichtlichen Schilderungen und auch molekulargenetischen Daten zufolge, ihren Ausgang in China (Morelli et al. 2010: 1140-1143) und forderte in Europa bis zu 25 Millionen Todesopfer. Von der Zeit des Schwarzen Todes an traten immer wieder einzelne Pestepidemien bis zum Beginn des 18. Jahrhunderts auf (die hier, nicht ganz treffend, als mittelalterliche Pest zusammengefasst werden). Der letzte große Pestausbruch erfolgte 1720-1722 in Marseille (z.B. Vasold 2008). Nach Bergdolt (2006) stellt diese Pandemie und die darauffolgenden Epidemien einen der großen, europäischen Erinnerungsorte dar. Seit Jahrhunderten verbindet man mit der Pest Leiden, Verzweiflung, ein einsames und qualvolles Sterben, die Auflösung gesellschaftlicher Bindungen, den Verlust religiöser oder weltanschaulicher Sicherheit und einen menschlichen Ausnahmezustand. Der schwarze Tod hatte enorme Auswirkungen in allen Bereichen der Gesellschaft. So werden beispielsweise die mittelalterlichen Judenmorde und Geißlerzüge mit der Angst vor der Pest begründet, verschiedene Versorgungskrisen und wirtschaftliche Krisen durch den Bevölkerungs- rückgang verursacht, spezielle Schutzpatrone gegen die Pest etabliert und die Pest als Thema der bildenden Kunst spätestens ab der Barockzeit etabliert (Bergdolt 2006, Achilles-Syndram 1995: 94-122, Dormeier 1995: 54-94, Wilderotter 1995: 12-53).

\section{Wirklich die Pest?}

Das Wissen um die Art der Erkrankung, die in einer Bevölkerung grassiert, ist zentrales Thema der Geschichte. Nur so wird ermöglicht, das Auftreten und die Verbreitung einer historisch bekannten Epidemie mit ihren sozialen und physischen Umwelten und der Alltagserfahrung der Menschen in Verbindung zu bringen. Krankheiten sind sicherlich zum Teil ein kulturelles Konstrukt und die moderne Pesterfahrung lässt sich nicht in allen Punkten mit der vorantibiotischen historischen Pesterfahrung vergleichen (siehe hierzu Cunningham 1992: 209-244). Allerdings liegt einer Erkrankung eine pathologische Realität zugrunde. Die Kenntnis der Ursache einer Erkrankung führt nicht nur dazu das individuelle Leiden der Erkrankten nachzuzeichnen, sondern auch Fragen bezüglich der Umweltbedingungen, die einen Ausbruch und die Verbreitung der Krankheit erlaubt haben, zu beantworten.

Die Diagnose Pest ist insbesondere für die antiken Epidemien bis zum dritten Jahrhundert in Frage zu stellen. So werden, aufgrund der historischen Beschreibung des Krankheitsbildes, als Verursacher für die „Pest“ von Athen (430-426 v.Chr.) eher die Pocken angenommen (Retief and Cilliers 1998: 52-53), molekulargenetische Untersuchungen weisen allerdings auf Typhus hin (Papagrigorakis et al. 2006: 214). Ebenso wird für die frühen Pandemien im Römischen Reich eher eine Pocken-, Masern-, Hautleishmaniose- oder auch Malaria- Infektion als die eigentliche Pest angenommen (Übersicht bei Retief and Cilliers 2000: 267-272). 
Kontrovers diskutiert wird ebenfalls, ob es sich bei den durch historische Quellen besser erfassbaren Epidemien des Justinianischen Zeitalters und des Schwarzen Todes wirklich um die durch $Y$. pestis verursachte Infektionskrankheit Pest handelt (Übersicht bei Benedictow 2011). Gegen die Diagnose Pest spricht, dass das epidemiologische Geschehen im Mittelalter zum Teil von der Pandemie im 19ten Jahrhundert abweicht und sich häufig nicht schlüssig durch den klassischen Pestzyklus Hausratte - Rattenfloh - Mensch erklären lässt (Übersicht bei Vasold 2003, 2008). Als Alternative zu der von $Y$. pestis verursachten Pest werden für diese Pandemien andere Infektionen wie Anthrax (Twigg 1984) und ein hämorrhagisches Fieber (Duncan und Scott 2005: 319) postuliert.

Die Untersuchung von archäologischem Material auf die DNA des Pesterregers kann also nicht nur dazu dienen die Krankheit in der jeweiligen untersuchten Population nachzuweisen, sondern auch dazu beitragen, diese Diskussion um den Erreger historischer „Pest"-Pandemien zu beenden.

\section{DAS ARCHÄOLOGISCHE MATERIAL}

In den hier vorgestellten Studien wurde von zwei verschiedenen Fundorten, die in den Zeitraum der zwei großen historischen Pestpandemien fallen, archäologisches Skelettmaterial auf die Anwesenheit des Erregers Y. pestis untersucht.

\section{Frühmittelalterliches Gräberfeld Aschheim - Bajuwarenring}

Auf dem Gebiet der heutigen Gemeinde Aschheim kamen an mehreren Stellen bajuwarische Gräber zu Tage. Die Nekropole der frühmittelalterlichen Siedlung (Aschheim-Bajuwa- renring, Lkr. München, Bayern, Deutschland) wurde schließlich in den Jahren 1997 und 1998 geborgen, sie datiert in die Zeit des 6. und 7. Jahrhunderts nach Christus. Insgesamt enthält das Gräberfeld 402 Körpergräber mit insgesamt 444 Bestatteten. Aufgrund der Bestattungsanzahl und der Belegungsdauer der Nekropole kann auf eine durchschnittliche Größe der dazugehörigen Siedlung von nur geschätzten 66 Individuen geschlossen werden (Staskiewicz 2007: 41), so dass davon ausgegangen werden kann, dass hier eine kleine ländliche Gemeinschaft vorlag. Ein auffallendes Merkmal des Gräberfeldes Aschheim-Bajuwarenring sind die vielen Doppel- und Mehrfachbestattungen (insgesamt acht Prozent der Gräber). Diese sind nicht gleichmäßig über den Belegungszeitraum verteilt, sondern konzentrieren sich im Wesentlichen auf zwei Zeitabschnitte: Zum einen in das mittlere Drittel des 6. Jahrhunderts, zum anderen an das Ende des 6. Jahrhunderts. (GutsmiedlSchümann 2010). Dies führte zu der Vermutung eines Zusammenhangs dieser Mehrfachbestattungen mit der Justinianischen Pest, die zu dieser Zeit weiter südlich in Italien geherrscht haben dürfte.

Aus dieser Überlegung heraus wurden zwei Individuen (166 und 167) eines der Doppelgräber molekulargenetisch auf $Y$. pestis untersucht (Wiechmann and Grupe 2005: 48). Diese waren mit einem reichen Beigabenensemble ausgestattet. Insbesondere fiel auf, dass zwischen den Oberschenkeln der beiden Bestatteten je eine Fibel eines Bügelfibelpaares vom nordischen Typ lag (Gutsmiedl-Schümann 2005, siehe Abbildung 1) Eine der beiden hier bestatteten Frauen starb juvenil (13-16 Jahre), während die andere ein spätadultes Alter (ca. 48 Jahre) erreichte (Staskiewicz 2007: 51). Die Bestattungssituation führte dementsprechend zu der Vermutung, dass es sich bei diesen beiden Individuen um Verwandte gehandelt haben könnte, was ebenfalls molekulargenetisch überprüft werden sollte. 

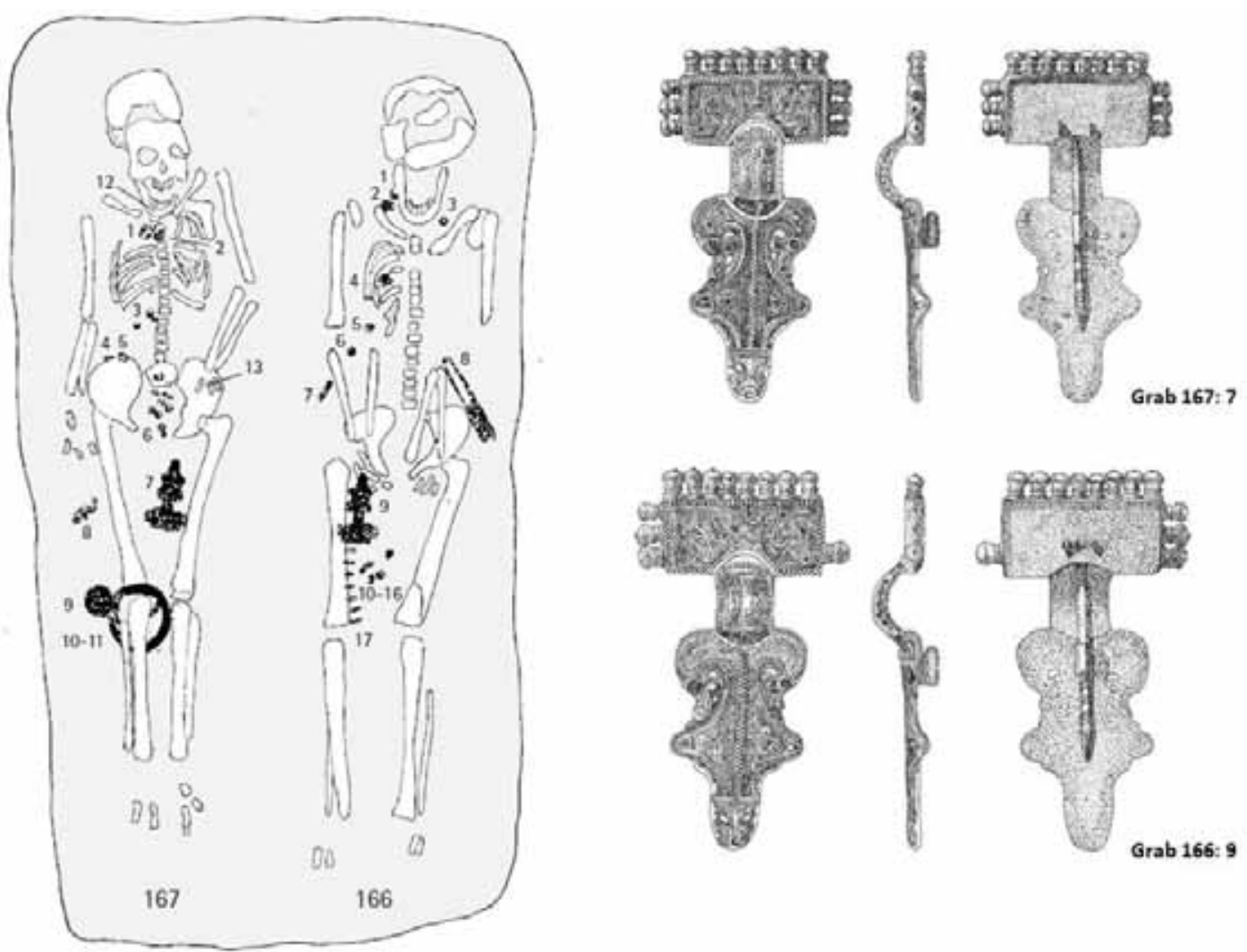

Abbildung 1:

Links: Doppelgrablege mit Individuen 166 und 167 aus dem frühmittelalterlichen Gräberfeld AschheimBajuwarenring (Bayern, Deutschland). Rechts: Je eine Fibel eines Bügelfibelpaares vom nordischen Typ, welche bei jedem Individuum zwischen den Oberschenkeln lag (Nr. 7 bei Individuen 167, Nr. 9 bei Individuum 166). Abbildung aus Gutsmiedl-Schümann 2005.

\section{Mittelalterliches Massengrab Manching-Pichl}

Während einer im Jahr 1984 stattgefundenen Renovierung der katholischen Pfarrkirche St. Leonhard im Ort Pichl, Gemeinde Manching, Landkreis Pfaffenhofen an der Ilm (Bayern, Deutschland), wurden im Erdreich unterhalb der Sakristei zahlreiche Skelettfunde freigelegt. Der archäologische Befund ergab 75 Skelette sowie einige Sammelfunde. Im Vergleich zum üblichen Aussehen eines mittelalterlichen Dorffriedhofes handelte es sich bei der vorgefundenen Grabstätte um einen ungewöhnlichen Fund: Die Skelettindividuen lagen dicht gedrängt in vier Schichten übereinander (Abbildung 2). Einzelne Grabgruben, also zeitlich getrennte Aushebungen, konn- ten nicht festgestellt werden. Für die Toten wurde augenscheinlich kaum eine Grube ausgehoben; die Toten wurden vielmehr beinahe ebenerdig niedergelegt und schichtweise mit Sediment bedeckt. All diese Details zeigen, dass es sich bei den aufgefundenen Skelettfunden um ein Massengrab handelt. Da keine Grabbeigaben vorlagen, konnte eine zeitliche Zuordnung der Skelette nur anhand begleitender Bauelemente erfolgen. Baubefund und Baumaterialien führten zu der Hypothese, dass es sich bei dem Fund um ein Massengrab handeln könnte, in dem die Opfer einer Pestwelle der großen Pandemie des „Schwarzen Todes“ des 14. Jahrhunderts bestattet worden waren. (Garrelt and Wiechmann 2003: 247) Für die Überprüfung der Funde auf $Y$. pestis wurden 33 Individuen ausgewählt. 


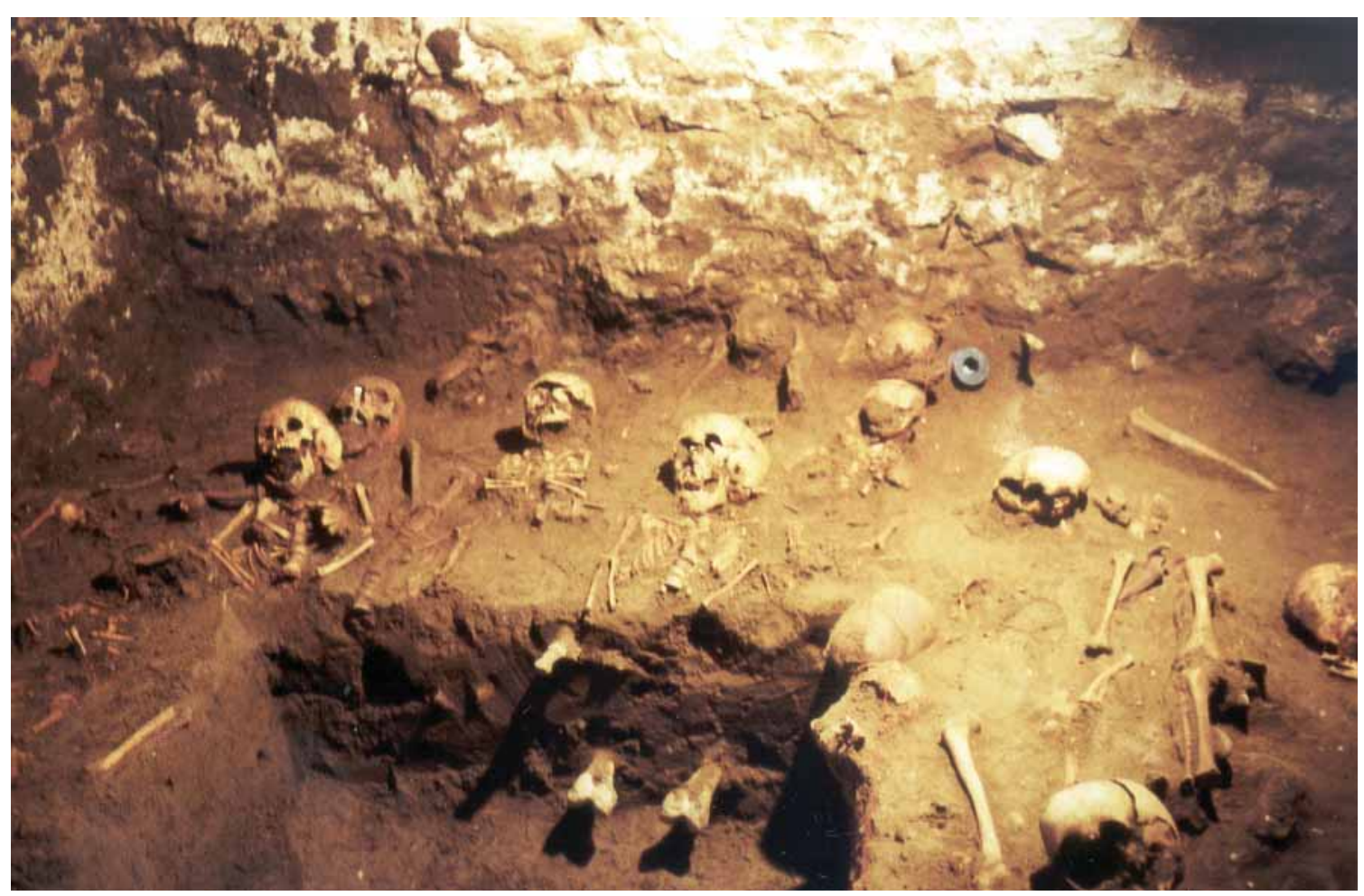

Abbildung 2:

Mittelalterliches Massengrab unterhalb der Sakristei der Pfarrkirche St. Leonhard (Manching-Pichl, Bayern, Deutschland), mit freundlicher Genehmigung des Bayerischen Landesamtes für Denkmalpflege.

\section{METHODEN}

Der Nachweis bakterieller Erreger von Infektionskrankheiten in archäologischem Skelettmaterial gelingt über die Detektion spezifischer Abschnitte der DNA des Erregers. So kann sich z. B. im Falle der Pest der Erreger Y. pestis zum Zeitpunkt des Todes des Individuums in seiner Blutbahn befinden. Auch nach dem Tode und der Skelettierung können daher nicht nur DNA-Reste des Individuums selbst, sondern auch von $Y$. pestis in den Überresten des Pestopfers vorhanden sein.

\section{Generelle Betrachtung zur Analyse alter DNA}

Die Analyse von alter DNA stellt besondere methodische Anforderungen, verursacht durch die Instabilität von Nukleinsäuren nach dem Tod des Individuums. In toten Geweben sammeln sich
DNA-Schäden aufgrund spontaner Hydrolyse und Oxidation an, was dazu führt, dass viele archäologische Proben keine DNA mehr enthalten. Ist noch Erbinformation vorhanden, ist sie durch Strangbrüche, Basenverluste, fehlkodierende Läsionen und Quervernetzungen gekennzeichnet. So resultieren erhöhte methodische Anforderungen bei der Analyse von alter DNA und es lassen sich überwiegend nur kleine Fragmente wiedergewinnen. (Willerslev and Cooper 2005: 5-6).

Bei dem meist unumgänglichen Einsatz des Verfahrens der Polymerasekettenreaktion (PCR) werden zudem bevorzugt unbeschädigte Nukleinsäuren vervielfältigt, was die Gefahr von Kontaminationen stark erhöht (Willerslev und Cooper 2005: 6). Daher sind viele molekulargenetische Nachweise von Erreger-DNA umstritten (z. B. Barnes and Thomas 2006: 651; Gilbert et al. 2004: 342). Die Ursache hierfür liegt in der unzureichenden Sicherung der Authentizität der 
gewonnenen Daten (Roberts and Ingham 2008: 609). Die Problematik besteht in noch stärkerem Ausmaß bei der Analyse von menschlicher DNA, da sich hier ungleich größere Kontaminationsmöglichkeiten z. B. mit der DNA der archäologischen und anthropologischen Bearbeiter bieten. So bestehen für die Analyse von aDNA besondere Richtlinien (z.B. Gilbert et al. 2005: 541), welche die Authentizität der gewonnenen aDNA-Ergebnisse sichern sollen. Unter anderem ist ein speziell für diese Anforderungen ausgestatteter Reinstraum notwendig, in dem ausschließlich mit alter DNA gearbeitet wird, um Kontaminationen mit modernem Probenmaterial zu vermeiden. Hier wird die DNA aus dem Skelettmaterial extrahiert und es werden Analyseschritte vor der Vervielfältigung durchgeführt. Um Kontaminationen mit schon vervielfältigter DNA (Amplifikate) aus vorherigen Studien zu vermeiden, sollte dieser Reinstraum vollständig räumlich und logistisch getrennt von allen Analyseschritten sein, bei denen mit mittels PCR vervielfältigter DNA gearbeitet wird.

\section{Molekulargenetische Detektion von Y. pestis}

Für die DNA-Analyse wurden ausschließlich Zähne verwendet, da hier sowohl die Quantität als auch die Qualität der DNA erfahrungsgemäß höher ist. Es wurden weiterhin sogenannte Negativkontrollen sowohl bei der Extraktion als auch bei den PCRs mitgeführt; diese sollen eine ggf. eingeschleppte Kontamination während des Analyseprozesses detektieren. Verwendete Arbeitsgeräte sowie Arbeitsflächen wurden - je nach Materialbeschaffenheit - mit Natriumhypochlorit $(\mathrm{NaOCl})$ bzw. Aceton gereinigt sowie UV-bestrahlt, weiterhin wurden nur als DNA-frei deklarierte Chemikalien zur Analyse verwendet.

Abbildung 3 zeigt eine Übersicht über den im Folgenden beschriebenen Arbeitsablauf:

Nach dem Reinigen der Proben (Details siehe bei Wiechmann and Grupe 2005: 49), werden diese mittels Kugelschwingmühle homogenisiert. Aus dem entstehenden Knochenmehl wird die DNA nach einem Protokoll basierend auf dem von Yang et al. (1998: 540) extrahiert. Anschließend werden für Y. pestis spezifische DNA-
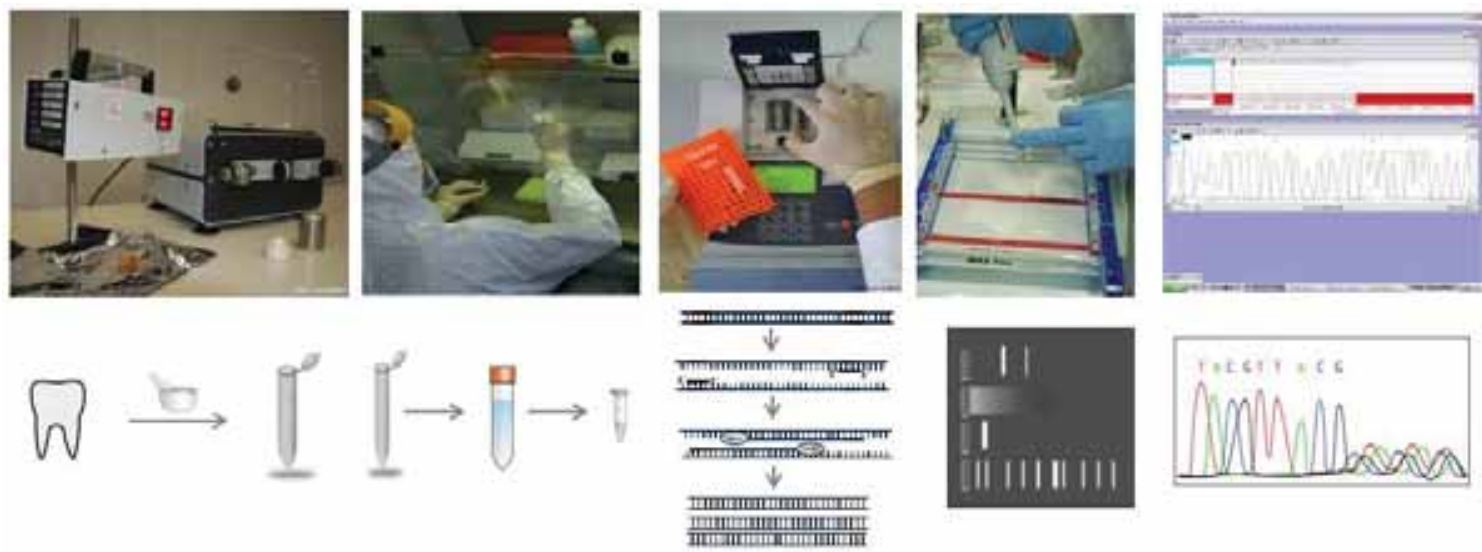

IIIIIIII

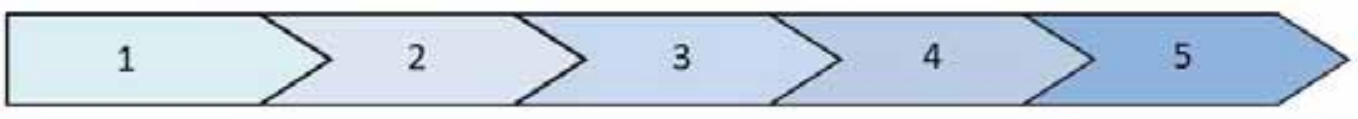

Abbildung 3:

Arbeitsablauf der Analyse von alter DNA (Fotos Lisa Seifert). 1: Reinigen und Homogenisieren des Zahnmaterials, 2: Extraktion der DNA, 3: Vervielfältigung definierter DNA-Fragmente mittels Polymerasekettenreaktion (PCR), 4: Überprüfung des PCR-Erfolges mittels Gelelektrophorese, 5: Sequenzierung und Auswertung 
Fragmente gezielt mittels des Verfahrens der PCR amplifiziert. Dabei handelt es sich um Abschnitte eines Plasmids des Bakteriums (pPCP1), das im Gegensatz zur chromosomalen DNA in erhöhter Kopienzahl vorliegt und so zur Analyse besonders geeignet ist (Parkhill et al. 2001: 523). Als Referenz diente die in GenBank veröffentlichte Nukleotidsequenz des Plasmids pPCP1 von Y. pestis Stamm CO92 (GenBank accession no. AL109969.1).

Bei allen Individuen wurde versucht den Sequenzabschnitt 7116 - 7263 (148 bp) des auf dem Plasmid pPCP1 lokalisierten pla-Gens (plaRegion 1) zu amplifizieren (Abbildung 4). Dafür wurde das zuvor von Raoult et al. (2000: 12801) beschriebene Pimerpaar YP12D/YP11R genutzt. Bei einigen Individuen wurde darüber hinaus das ebenfalls von Raoult et al. (2000: 12801) beschriebene Primerpaar YP11D/YP10R eingesetzt (pla-Region 2, Position 7242 - 7389).

Ein weiterer Sequenzabschnitt (130 bp) des pla-Gens ließ sich mit dem Primerpaar YP14F/ YP13R amplifizieren (pla-Region 3, Position 6953 - 7082). Zum Einsatz kamen ferner das
Primerpaar pst-F/pst-R, mit dem ein Sequenzabschnitt (129 bp) des pst-Gens (Abb. 4) amplifiziert werden kann (Position 5026 - 5154), sowie das Primerpaar PCP-F/PCP-R, mit dem ein weiterer, 130 bp langer Sequenzabschnitt (Position 8428 - 8557) auf dem Plasmid vervielfältigt werden kann. Die Primersequenzen und PCR-Bedingungen entnehme man Wiechmann and Grupe (2005: 49-50) sowie Wiechmann et al. (2010: 1806).

Um festzustellen, ob die entsprechenden Fragmente erfolgreich amplifziert werden konnten, wurden die PCR-Produkte anschließend gelelektrophoretisch aufgetrennt. Mit diesem Verfahren lassen sich die gewonnenen Amplifkate nach ihrer Größe auftrennen. Gleiche Moleküle laufen in diskreten Zonen (Banden) bei Anlegen eines elektrischen Feldes durch das Gel. Die DNA wird durch Silberfärbung (Protokoll siehe Wiechmann and Grupe 2005: 50) sichtbar gemacht und die Größe der DNA-Fragmente kann durch Abgleich mit einem mitlaufenden Standard (DNALeiter) abgeschätzt werden.

Konnte eine Bande der erwarteten Fragmentlänge auf dem Gel nachgewiesen werden,

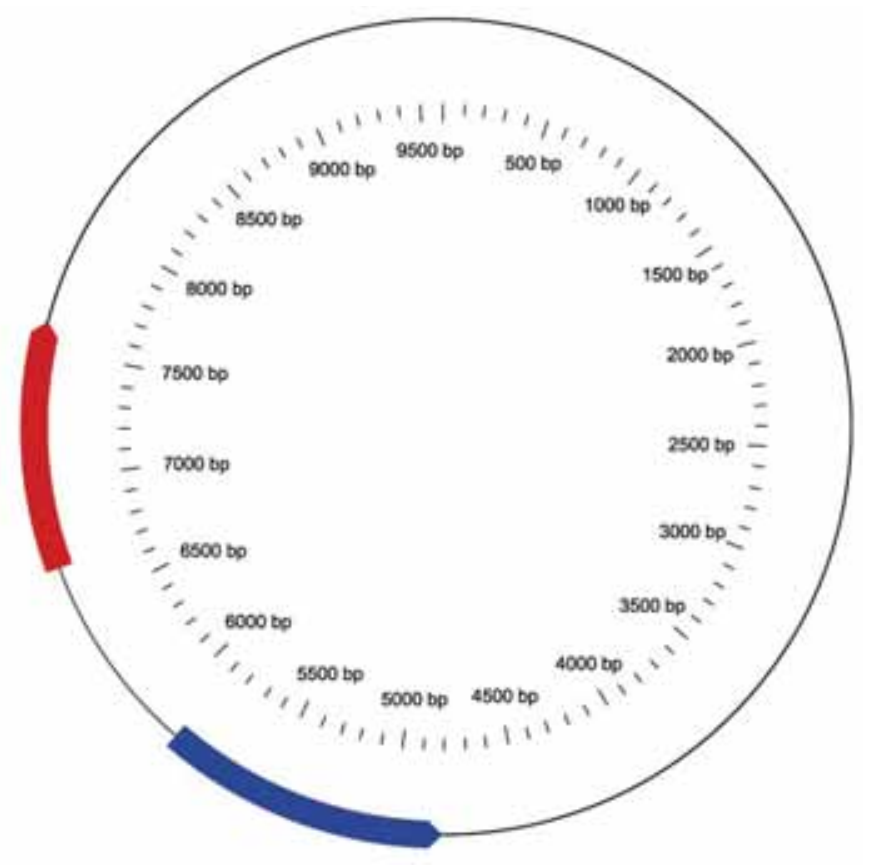

Abbildung 4:

Plasmid pPCP1 von Y. pestis. Roter Pfeil: pla-Gen, blauer Pfeil: pst-Gen. 
wurde das Amplifikat anschließend sequenziert (mittels Sanger-Sequenzierung, Protokolle siehe Wiechmann and Grupe 2005: 51, Wiechmann et al. 2010: 1806), d.h. die Basen-Abfolge des erhaltenen DNA-Moleküls (Sequenz) wurde dargestellt.

\section{Verwandtschaftsanalyse}

Der prinzipielle Ablauf einer Verwandtschaftsanalyse bei alter DNA entspricht dem der molekulargenetischen Detektion von $Y$. pestis (Abbildung 3).

Dabei werden bestimmte Abschnitte der DNA des Individuums mittels PCR vervielfältigt, die dazu geeignet sind Auskunft über verwandtschaftliche Beziehungen zu geben. Hierbei handelt es sich z. B. um die Hypervariable Region I (HVRI) der mitochondrialen DNA. Mitochondrien befinden sich beim Menschen zusätzlich zur chromosomalen DNA in der Zelle und liegen im Gegensatz zu dieser in erhöhter Kopienzahl vor. Dementsprechend ist ihre Erhaltungswahrscheinlichkeit gegenüber der chromosomalen DNA (ebenso wie bei den Plasmiden von Y. pestis) erhöht. Mitochondriale DNA wird ausschließlich mütterlich vererbt, abgesehen von Mutationen stimmt also die mtDNA jeder Person mit jener ihrer Mutter, ihrer Geschwister und ihrer Verwandten der mütterlichen Linie überein. Diese beiden Eigenschaften (gute Erhaltungswahrscheinlichkeit, nur mütterliche Vererbung) machen die mitochondriale DNA so gut geeignet für genealogische Untersuchungen von skeletalen Überresten.

Eine Verwandtschaftsanalyse wurde für die zwei frühmittelalterlichen Individuen aus Aschheim durchgeführt. Der amplifizierte mtDNASequenzbereich umfasste unter Einbeziehung von zwei überlappenden Amplifikationsprodukten insgesamt 354 bp (Position 16056 bis 16409, Nummerierung nach rCRS, Andrews et al. 1999). Primerpaare und PCR-Bedingungen entnehme man Wiechmann and Grupe (2005: 49-50). Die erhaltenen Amplifikate wurden wiederum mittels Gelelektrophorese aufgetrennt und bei erfolgreicher Signaldarstellung sequenziert. Die erhaltenen Sequenzen wurden anschließend miteinander verglichen, um eine mütterliche Verwandtschaft der Individuen zu überprüfen. Chromosomale DNA war leider nicht ausreichend erhalten, um eine Aussage zur Verwandtschaft der beiden Individuen zuzulassen, so dass die Darstellung dieser Analysen hier ausgespart bleibt (vgl. Wiechmann and Grupe 2005: 52).

\section{ERGEBNISSE}

Es gelang bei Individuen beider Grabgruppen $Y$. pestis-spezifische DNA-Abschnitte nachzuweisen. In beiden Studien blieben alle mitgeführten Negativkontrollen (Extraktions- und PCR-Kontrollen) ohne Befund. Die Standards für die Analyse alter DNA wurden eingehalten. Daher ist davon auszugehen, dass die im Folgenden vorgestellten Ergebnisse authentisch sind.

\section{Frümittelalterliches Doppelbegräbnis Aschheim-Bajuwarenring}

Für beide Individuen konnten $Y$. pestisspezifische Fragmente der pla-Region 1 (siehe Methoden) gewonnen werden. Die Sequenzresultate der Amplifikate ergaben eine 99\% - 100\%ige Übereinstimmung mit der in GenBank (Accession no. AL109969.1) veröffentlichten Nukleotidsequenz (Nukleotide 7136-7241) des auf dem $Y$. pestis-spezifischen Plasmids pPCP1 lokalisierten pla-Gens (Parkhill et al. 2001).

Es gelang von beiden Individuen der Doppelgrablege mitochondriale DNA-Fragmente der HVRI - Region zu gewinnen. Beide Individuen weisen die gleichen Abweichungen von der Referenzsequenz rCRS auf: 16069 T, 16126 C, 16145 A, $16231 \mathrm{C}, 16261 \mathrm{~T}$.

Daraus lässt sich eine mögliche Zuordnung zur mitochondrialen Haplogruppe J vermuten, welche häufig in Europa und dem Nahen Osten vorkommt (nach van Oven und Kayser 2009), eine sichere Zuordnung wäre allerdings nur durch die Einbeziehung weiterer Regionen möglich.

Der vorgefundene Haplotyp weist in der Empop-Datenbank (http://empop.org/, Version 
2.1, Release 5) eine Häufigkeit von $2.007 \mathrm{e}^{-3}$ auf, d.h. nur 21 von 10261 untersuchten Individuen in dieser Datenbank weisen diese spezifische HVR I - Sequenz auf. Eine Verwandtschaft der beiden Individuen über die mütterliche Linie ist damit relativ sicher anzunehmen.

\section{Mittelalterliches Massengrab Manching-Pichl}

Bei den Individuen des Massengrabes von Manchig-Pichl konnten bei 10 von 33 untersuchten Individuen positive Signale bei Amplifizierung der pla-Region 1 erzielt werden (Garrelt and Wiechmann 2003: 252). Um zu überprüfen, ob die erhaltenen Amplifikate tatsächlich den gesuchten $Y$. pestis-spezifischen DNA-Sequenzabschnitt aufweisen, wurden Amplifikationsprodukte von fünf Individuen sequenziert. Die Sequenzresultate ergaben eine $94 \%$ - 100\%ige Übereinstimmung mit der in GenBank veröffentlichten Referenzsequenz (GenBank accession no. AL109969.1). Die

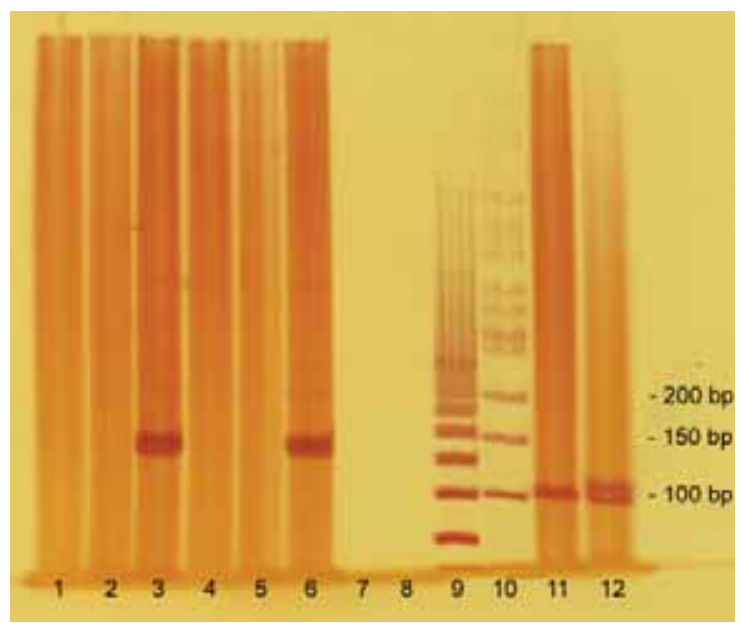

Abbildung 5:

Silbergefärbtes Polyacrylamidgel, das aus alter DNA amplifizierte $Y$. pestis pla-Fragmente (130 bp) aufzeigt (Spuren 3 und 6). Spuren 1 - 6: DNA-Extrakte menschlicher Zahnproben (Manching-Pichl, Bayern), Spur 7: Extraktionskontrolle, Spur 8: PCR-Negativkontrolle, Spur 9: 20 bp DNA-Leiter, Spur 10: 50 bp DNA-Leiter, Spuren 11 und 12: Amelogenin-Marker zur Geschlechtsbestimmung. beobachteten Sequenzabweichungen beruhen höchstwahrscheinlich auf Degradationsprozessen in der DNA während der Liegezeit. Degradationsbedingte Sequenzartefakte kommen in alter DNA häufig vor und erklären sich durch Desaminierung bedingte Modifikationen in der template DNA (Hofreiter et al. 2001: 4797).

Das Ausbleiben eines Amplifikationserfolges bei 23 der 33 untersuchten Individuen ist indes nicht als Negativbefund zu bewerten. Das Ausbleiben eines positiven Signals kann, neben methodischen Gründen, vielerlei Ursachen haben, z. B., dass der Erreger sich nicht in die Blutbahn des Individuums ausgebreitet hatte, die ErregerDNA nicht erhalten geblieben ist oder das entsprechende Individuum tatsächlich nicht mit $Y$. pestis infiziert war. Daher sind Negativbefunde bei dem Versuch molekulargenetisch Erreger-DNA nachzuweisen prinzipiell nicht aussagekräftig.

Die weiterführenden Analysen konzentrierten sich auf sechs Individuen des Massengrabes von Manchig-Pichl, deren DNA-Extrakte für die pla-Region 1 bereits positiv getestet werden konnten. In Abbildung 5 ist beispielhaft ein silbergefärbtes Polyacrylamidgel mit entsprechend angefärbten DNA-Amplifikaten der pla-Region 3 zu sehen.

Eine Zusammenstellung aller bei Individuen aus Manching-Pichl hinsichtlich Y. pestis-DNA bislang erfolgten Analysen ist in Tabelle 1 dargestellt. In dieser Tabelle ist auch zu ersehen, dass es nur bei drei der zehn für die pla-Region 1 positiv getesteten Individuen gelang den Befund häufig zu reproduzieren.

Die Ursache hierfür mag darin liegen, dass die Quantität der DNA in den nur vereinzelt amplifizierbaren Proben am Detektionslimit der verwendeten PCR lag, so dass es vom Zufall abhing, ob genügend Matrizen für eine Vervielfältigung in die PCR-Reaktion eingesetzt werden konnten. Wie man in Tabelle 1 erkennt, ist es aber auch nur bei den drei häufig reproduzierbar amplifzierbaren Proben gelungen, weitere Abschnitte des 


\begin{tabular}{|c|c|c|c|c|c|c|c|}
\hline $\begin{array}{l}\text { Individuum/ } \\
\text { individual }\end{array}$ & $\begin{array}{l}\text { Sterbealter/ } \\
\text { age at death }\end{array}$ & $\begin{array}{l}\text { Geschlecht/ } \\
\text { sex }\end{array}$ & $\begin{array}{l}\text { YP12D/ } \\
\text { YP11R }\end{array}$ & $\begin{array}{l}\text { YP11D/ } \\
\text { YP10R }\end{array}$ & $\begin{array}{l}\text { YP14F/ } \\
\text { YP13R }\end{array}$ & $\begin{array}{l}\text { pst-F/ } \\
\text { pst-R }\end{array}$ & $\begin{array}{l}\text { PCP-F/ } \\
\text { PCP-R }\end{array}$ \\
\hline 1-I & adult & $\mathrm{w}$ & $0^{1} / 4^{2}$ & & & & \\
\hline 2 & adult & $\mathrm{m}$ & $0 / 4$ & & & & \\
\hline 5-I & $25-30$ & $\mathrm{~m}$ & $0 / 4$ & & & & \\
\hline $15-\mathrm{I}$ & $\sim 8$ & $\mathrm{~m}$ & $0 / 4$ & & & & \\
\hline $17-\mathrm{I}$ & $\sim 11$ & $\mathrm{~m}$ & $2 / 10$ & $0 / 1$ & $0 / 2$ & $0 / 1$ & $0 / 1$ \\
\hline 22 & $20-22$ & $\mathrm{w}$ & $1 / 6$ & $0 / 1$ & & & \\
\hline 26-I & adult & $\mathrm{m}$ & $1 / 4$ & & & & \\
\hline 28-I & $\sim 8$ & $\mathrm{~m}$ & $0 / 4$ & & & & \\
\hline 34-I & adult & $\mathrm{w}$ & $6 / 6$ & & & $1 / 1$ & $1 / 1$ \\
\hline 40 & $20-25$ & $\mathrm{~m}$ & $0 / 4$ & & & & \\
\hline 44-III & $\sim 5$ & $\mathrm{w}$ & $1 / 4$ & & & & \\
\hline 49-I & matur & $\mathrm{m}$ & $0 / 4$ & & & & \\
\hline 50 & adult & $\mathrm{w}$ & $0 / 4$ & & & & \\
\hline 64-I & matur & $\mathrm{w}$ & $0 / 4$ & & & & \\
\hline 67-II & matur & $\mathrm{m}$ & $0 / 4$ & & & & \\
\hline 73-I & $20-25$ & $\mathrm{~m}$ & $3 / 10$ & $0 / 2$ & $0 / 2$ & & \\
\hline 74 & adult & $\mathrm{w}$ & $0 / 4$ & & & & \\
\hline S1-I & $\sim 8$ & $\mathrm{~m}$ & $6 / 6$ & $4 / 4$ & & $1 / 1$ & $1 / 1$ \\
\hline S2-II & adult & $\mathrm{m}$ & $0 / 4$ & & & & \\
\hline S3-IIX & $12-14$ & $\mathrm{~m}$ & $1 / 4$ & & & & \\
\hline S3-IX & $11-13$ & $?$ & $0 / 4$ & & & & \\
\hline S4-III & adult & $\mathrm{w}$ & $0 / 4$ & & & & \\
\hline S4-IV & adult & $\mathrm{w}$ & $0 / 4$ & & & & \\
\hline S4-VI & $\sim 10$ & $\mathrm{~m}$ & $1 / 4$ & & & & \\
\hline S4-XX & $\sim 15$ & $\mathrm{w}$ & $9 / 10$ & $2 / 2$ & $2 / 2$ & $3 / 3$ & $2 / 3$ \\
\hline S8-III & matur & $\mathrm{w}$ & $0 / 4$ & & & & \\
\hline S8-VII & $20-25$ & $\mathrm{w}$ & $0 / 4$ & & & & \\
\hline S11-II & adult & $\mathrm{w}$ & $0 / 4$ & & & & \\
\hline S11-IV & matur & $\mathrm{m}$ & $0 / 4$ & & & & \\
\hline S13-I & $20-25$ & $\mathrm{w}$ & $0 / 4$ & & & & \\
\hline S13-IX & matur & $\mathrm{m}$ & $0 / 4$ & & & & \\
\hline S14-I & $15-16$ & $\mathrm{~m}$ & $0 / 4$ & & & & \\
\hline S15-I & matur & $\mathrm{m}$ & $0 / 4$ & & & & \\
\hline
\end{tabular}

Tabelle 1:

Zusammenfassung der erhaltenen Amplifikationsresultate für die getesteten Individuen aus der St. Leonhard-Kirche in Manching-Pichl. Diverse, auf Y. pestis-DNA ausgerichtete, Primerpaare wurden eingesetzt.

$1=$ Anzahl erfolgreicher Amplifikationen; $\quad 2$ = Anzahl der Amplifikationsreaktionen (PCRs), $\mathrm{m}=$ männlich; $\mathrm{w}=$ weiblich 
Plasmids pPCP1 zu vervielfältigen. Sequenzierte Amplifikate der pla-Region 2 resultierten in einer 96\% - 100\%igen Übereinstimmung mit der Referenzsequenz, wobei auch hier die beobachteten Sequenzabweichungen voraussichtlich auf durch Desaminierung bedingte Modifikationen in der template DNA zurückzuführen sind. Die Sequenzabschnitte der pla-Region 3 und des pst entsprachen der Referenzsequenz (GenBank accession no. AL109969.1) zu 100\%.

Abweichungen zu dieser Referenzsequenz wurden jedoch nach Sequenzierung der mit dem Primerpaar PCP-F/PCP-R erhaltenen Amplifikate beobachtet. So weisen die Sequenzen der untersuchten Individuen an den Nukleotidpositionen 8528-8532 nur $3 \mathrm{~T}$ auf, während die Referenzsequenz ( $Y$. pestis strain CO92, plasmid pPCP1, GenBank accession no. AL109969.1) an diesen Nukleotidpositionen $5 \mathrm{~T}$ zeigt (Wiechmann et al. 2010: 1807).

\section{DISKUSSION}

Im Falle der frühmittelalterlichen Doppelgrablege konnte der Erreger in beiden Individuen nachgewiesen werden. Damit ist als Todesursache dieser Frauen die Pest anzunehmen. Zusätzlich konnte eine Verwandtschaft der Individuen über die mütterliche Seite gezeigt werden. Die Art der Verwandtschaft kann allerdings nicht näher eingegrenzt werden, Abbildung 6 zeigt ein Schema der Vererbung der mitochondrialen DNA - wie man sieht, kommen sowohl ein Mutter/TochterVerhältnis, als auch z.B. Großmutter/Enkelin, Cousinen oder Tante/Nichte - Interpretationen in Frage. Ein enges Verwandtschaftsverhältnis erscheint allerdings nicht nur aufgrund der Bestattungssituation wahrscheinlich, sondern wird auch von den archäologischen Funden unterstützt - die beiden Individuen teilen sich ein identisches Bügelfibelpaar (siehe Abbildung 1), welches als re-

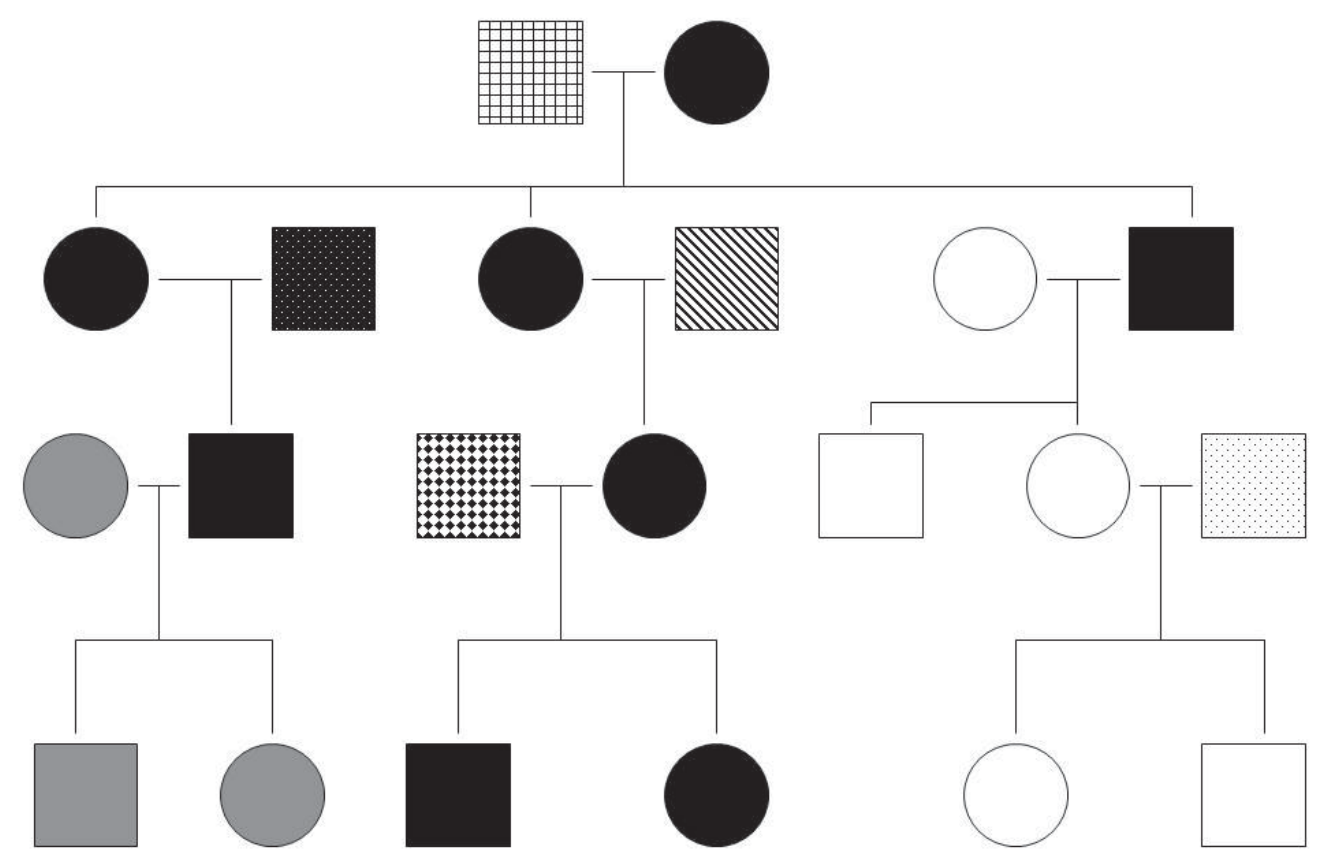

Abbildung 6:

Mütterliche Vererbung der mitochondrialen DNA für 21 Individuen in einem hypothetischen Stammbaum. Quadrate repräsentieren Männer, Kreise Frauen. Jeder mtDNA-Typ (Haplotyp) wird durch ein unterschiedliches Muster repräsentiert. 
lativ wertvoll eingeschätzt werden darf und wahrscheinlich in der Familie vererbt wurde (Reimann et al. 2000: 84-85). Betrachtet man das Sterbealter der gemeinsam bestatteten Frauen - eine verstarb juvenil, die andere spätadult - erscheint daher eine Mutter/Tochter-Interpretation, am plausibelsten.

Im Falle des mittelalterlichen Massengrabes gelang es gut reproduzierbar nur bei $9 \%$ der untersuchten Individuen den Erreger $Y$. pestis nachzuweisen. Dieses Ergebnis entspricht den Studien anderer Arbeitsgruppen (z. B. Haensch et al. 2010: 2) und verdeutlicht die Schwierigkeiten bei der Gewinnung alter DNA aus skeletalen Überresten. In einigen Fällen konnten nur einige Regionen des untersuchten Plasmides amplifiziert werden, was wiederum den Ergebnissen anderer Arbeitsgruppen (z.B. Haensch et al. 2010: 2) entspricht und auf degradationsbedingte Schäden der DNA zurückzuführen ist.

Auch wenn bislang nur für drei Individuen aus dem Massengrab sicher nachgewiesen werden konnte, dass sie Opfer der Pest waren, sprechen die Fundumstände dafür (siehe oben), dass dies wahrscheinlich auch für die anderen Individuen der Grablege zutrifft.

Die wahrscheinlichste Erklärung für den Fund des Massengrabes unter der Sakristei ist dementsprechend eine Pestwelle im mittelalterlichen Manching-Pichl, die zu so einer hohen Anzahl von Opfern führte, dass ein Massengrab angelegt werden musste.

\section{Yersinia pestis und der}

\section{Schwarze Tod des Mittelalters}

Unsere Ergebnisse zum mittelalterlichen Massengrab von Manching-Pichl reihen sich in eine Reihe von weiteren Studien ein, die Y. pestis in mittelalterlichen Gräbern nachweisen konnten (Abbildung 7). Der molekulargenetische Nachweis von $Y$. pestis wurde zunächst für drei Skelettfunde einer Mehrfachbestattung aus dem 14. Jh. in Montpellier (Raoult et al. 2000: 12800-12803), für zwei Skelettfunde aus einem Massengrab des Jahres 1722 in Marseille sowie für zwei Skelettfunde aus einem Massengrab des Jahres 1590 im südfranzösischen Dorf Lambesc (Drancourt et al. 1998) beschrieben. Des Weiteren wurden Nachweise beschrieben von Drancourt et al. (2004: 1585-1592, 2007: 332-333), Fundorte Martigues sowie Dreux in Frankreich, Pusch et al. (2004: 485), Beinhaus in Stuttgart, Tran et al. (2011), Fundort Venedig, im Rahmen einer von Haensch et al. (2010) durchgeführten Studie (Fundorte Saint-Laurent-de-la-Cabrerisse, Frankreich, Bergen op Zoom, Niederlande und Hereford, England), sowie von Schuenemann et al. (2011) für das Londoner „East Smithfield“ Massengrab.

Neben dem reinen Nachweis von Y. pestisDNA in archäologischen Überresten ist es bei entsprechendem DNA-Erhalt auch möglich chromosomale Marker des Bakteriums zu untersuchen, die Aufschluss über die spezifische Variante von $Y$. pestis geben, welche die jeweilige Pestepidemie ausgelöst hat. Damit können Ausbreitungswege der Pestepidemien nachgezeichnet und die evolutive Entwicklung des Erregers aufgeklärt werden (siehe Haensch et al. 2010: 3).

Allerdings findet sich hier eine Diskrepanz bei den bisherigen Studien, in denen es gelungen ist diese Marker zu typisieren. Während Haensch et al. (2010: 5) und Schuenemann et al. (2011: 6) Erregerstämme in Skelettmaterial der zweiten Pandemie typisieren konnten, die in bestimmten Markern keinem der modernen $Y$. pestis-Varianten entsprechen, sondern „Vorläufertypen“ darstellen, finden Drancourt et al. (2007: 333) in Skelettmaterial der ersten und zweiten Pandemie molekulargenetische Hinweise, dass es sich bei dem gefundenen Erreger um Stämme des Typus 1. ORI (vgl. Haensch et al. 2010: 6) handelt. Da unterschiedliches Material untersucht wurde, ist die Möglichkeit nicht auszuschließen, dass beide Erregertypen im Mittelalter in unterschiedlichen Regionen aktiv waren. Unter Berücksichtigung phylogenetischer Aspekte der Evolution von $Y$. 


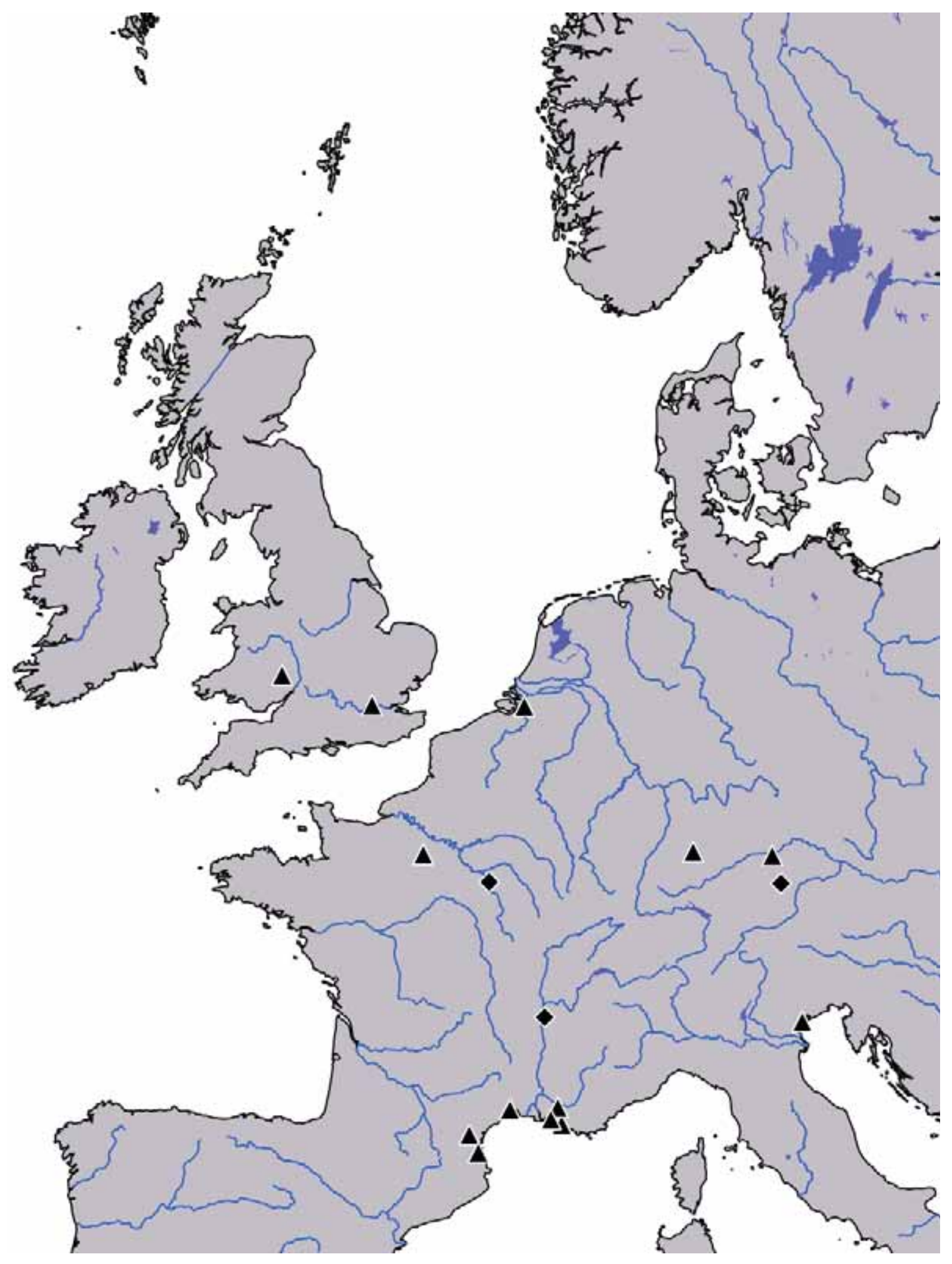

Abbildung 7:

Bisherige Pestnachweise an archäologischem Skelettmaterial, Dreiecke $=$ „,mittelalterliches“ Material, Rauten $=$ frühmittelalterliches Material. Daten aus Drancourt et al. (1998, 2004, 2007), Garrelt and Wiechmann (2003), Haensch et al. (2010), Pusch et al. (2004), Raoult et al. (2000), Schuenemann et al. (2011), Tran et al. (2011), Wiechmann and Grupe (2005) 
pestis ist dies allerdings nicht sehr wahrscheinlich. Dieser Widerspruch in den bisherigen molekulargenetischen Daten zu Y. pestis kann nur durch Analysen an weiteren $Y$. pestis-Bakterien aus mittelalterlichem Skelettmaterial auf ihre Variantenzugehörigkeit gelöst werden. Momentan werden dementsprechende Analysen an dem Material von Manching-Pichl durchgeführt, die damit einen Beitrag zur Beantwortung dieser Frage leisten sollen.

Insgesamt betrachtet kann man allerdings aus der vorhandenen und weiter wachsenden molekulargenetischen Datenlage schlussfolgern, dass $Y$. pestis der Verursacher der zweiten Pestpandemie war.

Dies wird unterstützt durch Ergebnisse aus immunchromatographischen Untersuchungen, die das pesteigene F1-Kapselprotein durch Reaktion mit dem Anti-F1-Serum darstellen (z.B. Kacki et al. 2011: 583-587). Aufgrund möglicher Kreuzreaktionen mit anderen bakteriellen Proteinen sind diese Tests allerdings unspezifischer bzw. unsicherer als ein DNA-Nachweis (Brandt et al. 2002: 313-314).

Der Nachweis von $Y$. pestis steht im scheinbaren Widerspruch dazu, dass die durch historische Quellen erschließbare Epidemiologie der mittelalterlichen Pest in einigen Fällen zum Teil nicht jener der gut dokumentierten Pandemie des 19ten Jahrhunderts entspricht, aus der sich der „klassische“ Ratten-Floh-Mensch-Zyklus ableitet.

Laut Stenseth et al. (2008: 0010), die die Ergebnisse mehrerer internationaler Konferenzen zum Thema zusammenfassen, zeigt allerdings die heutige Erfahrung mit modernen Pestausbrüchen, dass die klassische Pest-Epidemiologie, wie sie durch den klassischen Zyklus ausgelöst wird, nur eine von vielen Möglichkeiten ist. Dies liegt weitgehend an der komplexen Ökologie des Erregers (Gage and Kosoy 2005: 505-528) und einer Vielzahl von Übertragungswegen, die ebenfalls vom klassischen Bild abweichen können. Untersuchungen in Gegenden mit modernen Pestreservoirs zeigen, dass neben dem Ratte-Floh-Mensch-Weg weitere Möglichkeiten der Tier zu Mensch-Übertragung bestehen, z.B. Bisse von infizierten Tieren, durch den Verzehr von infiziertem Fleisch oder über Tröpfcheninfektion durch den Umgang mit infizierten Haustieren (Übersicht bei Stenseth et al. 2008: 0012). Neben der direkten Übertragung von Mensch zu Mensch durch Tröpfcheninfektion bei der Lungenpest können Mensch zu Mensch-Übertragungen wahrscheinlich auch durch den Menschenfloh oder Läuse (Ayyadurai et al. 2010: 892) vorkommen. Abbildung 8 fasst diese Möglichkeiten zusammen.

All diese Faktoren dürften das epidemiologische Erscheinungsbild der Erkrankung weiter komplizieren. Von Drancourt et al. (2006: 239) werden verschiedene Szenarien aufgeführt, die abhängig von den ökologischen Bedingungen zu unterschiedlichen Pestbildern führen können, einige seien hier exemplarisch genannt:

Sollte der Pesterreger in wilden Nagetierpopulationen vorkommen, aber keine humanen Ektoparasiten involvieren, kommt es zu sporadischen Ausbrüchen beim Menschen (durch den Verzehr von infiziertem Fleisch, Bissen von Nagern etc.).

Kommt der Pesterreger in wilden Nagetieren und Ratten vor und sind menschliche Ektoparasiten (Menschenfloh, Laus) involviert, resultiert dies in einer sich schnell von Ort zu Ort ausbreitenden Epidemie.

Eine reine Rattenpest hingegen ohne die Einbeziehung menschlicher Ektoparasiten resultiert in vielen menschlichen Opfern (Übertragung durch den Rattenfloh), allerdings mit einer begrenzten zeitlichen und räumlichen Ausbreitung.

$\mathrm{Zu}$ großen Pandemien beim Menschen kommt es, wenn die Rattenpest in Kombination mit menschlichen Populationen auftritt, die schwerwiegend mit menschlichen Ektoparasiten verseucht sind.

In Anbetracht der Komplexität der Pesterscheinung, die im Einzelnen nicht vollständig geklärt ist, erscheint es doch plausibel, dass die Epidemiologie von historischen Pestausbrüchen, insbesondere in klimatisch bzw. ökologisch verschiedenen Gebieten, von Ausbruch zu Ausbruch unterschiedlich sein dürfte. Ein epidemiologisches Geschehen, das nicht allein durch den Ratte-Floh-Mensch-Zyklus erklärt werden kann, ist dementsprechend kein zwingendes Argument gegen eine durch Y. pestis verursachte Epidemie. 


\section{Yersinia pestis und die Justinianische Pest}

Im Vergleich zum schwarzen Tod des Mittelalters liegen für das Justinianische Pestgeschehen bislang nur wenige molekulargenetische Studien an Skelettmaterial vor: Neben der hier vorgestellten Untersuchung gelang es bisher nur Drancourt et al. (2004: 1590-1591, 2007: 333) Y. pestis-DNA bei Skelettfunden aus frühmittelalterlichen Massengräbern bei den französischen Städten Sens (5tes bis 6tes Jh. n. Chr.) und Vienne (7tes bis 9tes Jh. n. Chr.) zu detektieren (Abbildung 7).

Diese bisherigen, vereinzelten molekulargenetischen Detektionen in frühmittelalterlichem Material sind allerdings als starker Hinweis dafür zu werten, dass auch die Justinianische Pest durch $Y$. pestis verursacht wurde. Um eine sichere Identifizierung von $Y$. pestis als Verursacher der Justinianischen Pandemie zu gewährleisten, müssten aufgrund der beschriebenen methodischen Schwierigkeiten bei der Analyse von alter DNA und damit verbundenen Möglichkeit der falsch positiven Signale (siehe oben) allerdings mehr molekulargenetische Daten erhoben werden.

Der hier vorgestellte Nachweis von $Y$. pestis in einem frühmittelalterlichen Gräberfeld Bayerns hat zudem eine große Bedeutung hinsichtlich der Ausbreitung der Justinianischen Pest: Da es keine bekannten historischen Texte gibt, die implizieren, dass die Justinianische Pest Bayern erreichte, liegt mit diesem Fund der einzige Nachweis dieser Art vor, der die Ausbreitung der Justinianischen Pest über das römische Reich hinaus in nördlichere Regionen bestätigt.

Die historische Quellenlage ließ dies vorher nur vermuten. So existieren Erwähnungen in keltischen und angelsächsischen Quellen über annähernd zeitgleich zur Justinianischen Pest auftretende Seuchenepidemien in Großbritannien (Maddicott 2007: 214), die allerdings das Krankheitsbild nicht ausführlich genug für eine Diagnose beschreiben. Weiterhin besteht Grund zur Vermutung, dass eine Epidemie, die $544 \mathrm{n}$.

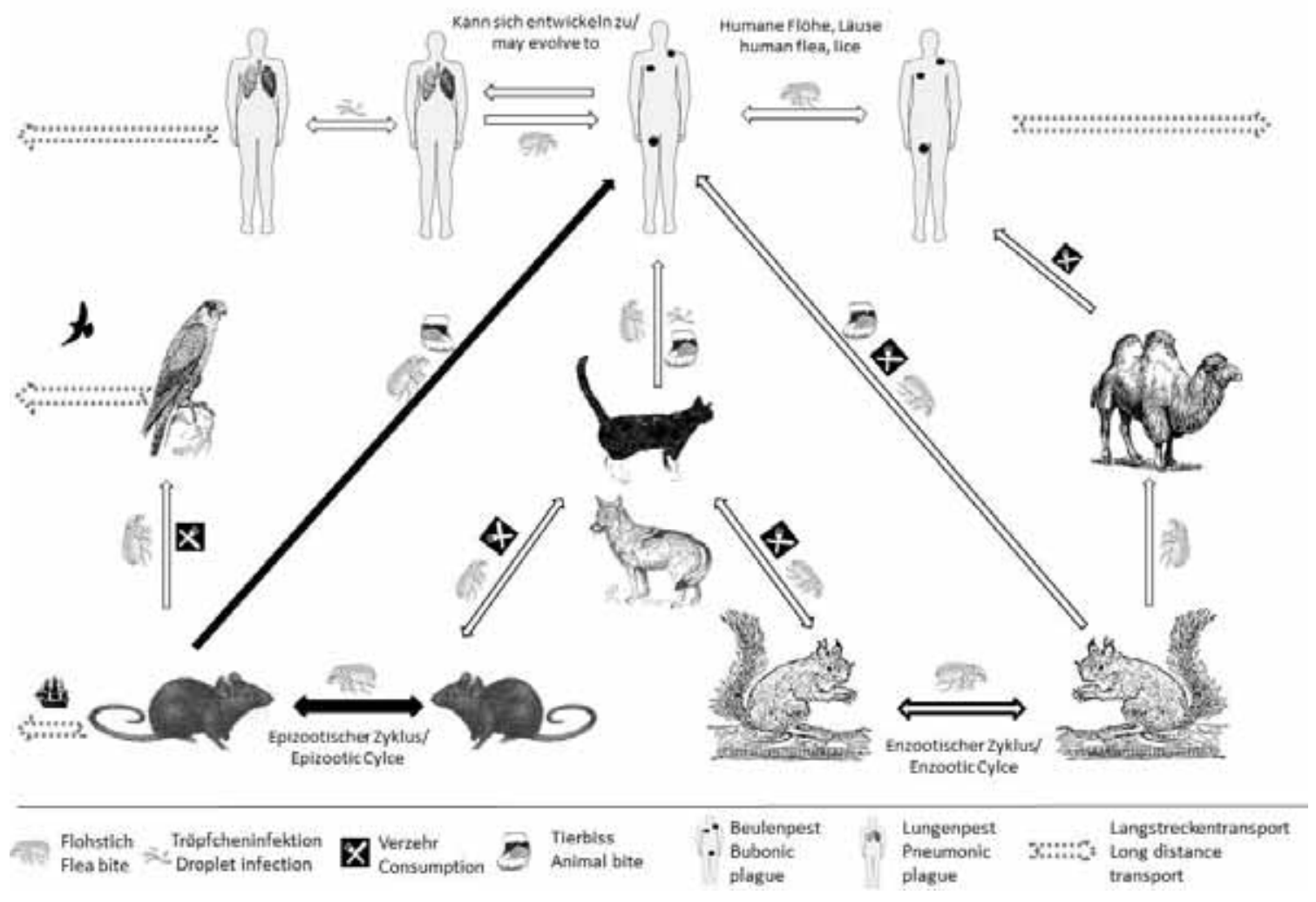

Abbildung 8:

Mögliche Übertragungswege von Y. pestis. Schwarze Pfeile deuten den sogenannten klassischen Übertragungsweg Ratte - Rattenfloh - Mensch an. 
Chr. in Irland auftrat (die ebenfalls aufgrund mangelnder Beschreibungen nicht eindeutig diagnostiziert werden kann), der letzte Ausläufer der ersten Welle der Justinianischen Pest durch Europa gewesen sein könnte (Dooley 2007: 228).

\section{AUSBLICK}

Die vorgestellte Untersuchung zeigt das große Potential, das die Anwendung molekulargenetischer Methoden zur Aufklärung historischer Epidemien hat. Dieses ist allerdings noch lange nicht ausgeschöpft. Viele Fragen, insbesondere für die Justinianische Pest, sind noch offen: Wie weit hatte sich die Pest ausgebreitet? Wo ist ihr Ursprung? Welche Variante von Y. pestis war ihr Verursacher? Hat sich die Virulenz des Pesterregers im Verlaufe der Zeit verändert, wie einige Autoren vermuten? Wie man in Abbildung 7 erkennen kann, sind die bisherigen Nachweise des Pesterregers an archäologischem Skelettmaterial auf einige westliche Regionen Europas beschränkt. Systematische molekulargenetische Analysen an weiterem archäologischem Material aus den entsprechenden Zeitepochen, die Funde aus den übrigen Teilen Europas und Asien miteinbeziehen, sind notwendig, will man den Verlauf der Pestepidemien charakterisieren und Informationen über die Evolution des Erregers gewinnen.

Offen ist ebenfalls die Frage nach den Verursachern der Epidemien der Antike vor der Justinianischen Pest. Auch hier könnte eine systematische molekulargenetische Analyse an geeignetem Material (z.B. aus Massengräbern dieser Zeitstellung) Aufschluss über den Erreger bringen.

\section{DANKSAGUNG}

Unser Dank gilt Frank Stremke, M.A., für seine Hilfe bei der Abbildungs- und Kartenerstellung.

\section{LITERATUR}

\section{Achilles-Syndram, K. 1995}

So macht nun Abbilder eurer Beulen und eurer Mäuse. Die Pest als Thema der bildenden Kunst, in: Das große Sterben. Seuchen machen Geschichte, H. Wilderotter (ed.), Dresden: Jovis, 94-122.

Andrews, R.M., Kubacka, I., Chinnery, P.F., Lightowlers, R.N., Turnbull, D.M. and Howell, N. 1999

Reanalysis and revision of the Cambridge reference sequence for human mitochondrial DNA, Nature Genetics 23: 147.

\section{Ayyadurai, S., Sebbane, F., Raoult, D. and \\ Drancourt, M. 2010}

Body Lice, Yersinia pestis Orientalis and Black Death, Emerging Infectious Diseases 16: 892893.

\section{Barnes, I. and Thomas, M.G. 2006 \\ Evaluating bacterial pathogen DNA preservation in museum osteological collections, Proceedings of the Royal Society B, 273: 645-653.}

\section{Benedictow, O.J. 2011}

What Disease was Plague? On the Controversy over the Microbiological Identity of Plague Epidemics of the Past, Leiden, Boston: Brill.

\section{Bergdolt, K. 2006}

Die Pest: Geschichte des Schwarzen Todes, München: C.H. Beck. 
Brandt, E., Wiechmann, I. and Grupe, G. 2002 How reliable are immunological tools for the detection of ancient proteins in fossil bones?, International Journal of Osteoarchaeology 12: 307-316.

\section{Cunningham, A. 1992}

Tranforming Plague: The Laboratory and the Identity of Infectious Disease, in: The laboratory revolution in Medicine, A. Cunningham and $\mathrm{P}$. Williams, (eds.), Cambridge: Cambridge University Press, 209-244.

Donoghue, H.D., Holton, J. and Spigelman, M. 2001

PCR primers that can detect low levels of Mycobacterium leprae DNA, Journal of Medical Microbiology 50: 177-182.

Donoghue, H.D, Spigelman, M., Greenblatt, C.L., Lev-Maor, G., Bar-Gal, G.K., Matheson, C., Vernon, K., Nerlich, A.G. and Zink, A.R. 2004

Tuberculosis: from prehistory to Robert Koch, as revealed by ancient DNA, Lancet Infectious Diseases 4: 584-592.

\section{Dooley, A. 2007}

The plague and its consequences in Ireland, in: Plague and the End of Antiquity. The Pandemic of 541-750, L.K. Little, (ed.), Cambridge: Cambridge University Press, 215-228.

\section{Dormeier, H. 1995}

Ein geystliche ertzeney fur die grausam erschreklich pestilenz. Schutzpatrone und frommer Abwehrzauber gegen die Pest, in: Das große Sterben. Seuchen machen Geschichte. H. Wilderotter, (ed.), Dresden: Jovis, 54-94.

Drancourt, M., Aboudharam, G., Signoli, M., Dutour, O. and Raoult, D. 1998

Detection of 400-year-old Yersinia pestis DNA in human dental pulp: An approach to the diagnosis of ancient septicemia, Proceedings of the $\mathrm{Na}$ tional Academy of Sciences of the United States of America 95: 12637-12640.

Drancourt, M., Houhamdi, L. and Raoult, D. 2006

Yersinia pestis as a telluric, human ectoparasiteborne organism, Lancet Infectious Diseases 6: 234-241.

Drancourt, M. and Raoult, D. 2005

Palaeomicrobiology: Current issues and perspectives, Nature Reviews Microbiology 3: 23-35.

Drancourt, M., Roux, V., Dang, L.V., TranHung, L., Castex, D., Chenal-Francisque, V., Ogata, H., Fournier, P.E., Crubezy, E. and Raoult, D. 2004

Genotyping, Orientalis-like Yersinia pestis, and plague pandemics, Emerging Infectious Diseases 10: 1585-1592.

Drancourt, M., Signoli, M., Dang, L.V., Bizot, B., Roux, V., Tzortzis, S. and Raoult, D. 2007 Yersinia pestis Orientalis in remains of ancient plague patients, Emerging Infectious Diseases 13: 332-333.

\section{Duncan, C.J. and Scott, S. 2005}

What caused the Black Death?, Postgraduate Medical Journal 81: 315-320.

\section{Gage, K.L. and Kosoy, M.Y. 2005}

Natural History of Plague: Perspectives from more than a century of research, Annual Review of Entomology 50: 505-528.

\section{Garrelt, C. and Wiechmann, I. 2003}

Detection of Yersinia pestis DNA in early and late medieval Bavarian burials, in: Documenta Archaeobiologiae 1. Decyphering ancient bones; the research potential of bioarchaeological col- 
lections, G. Grupe and J. Peters, (eds.), Rahden/ Westfalen: Leidorf, 247-254.

Gilbert, M.T.P., Cuccui, J., White, W., Lynnerup, N., Titball, R.W., Cooper, A. and Prentice, M.B. 2004

Absence of Yersinia pestis-specific DNA in human teeth from five European excavations of putative plague victims, Microbiology 150: 341-354.

Gilbert, M.T.P., Bandelt, H.-J.; Hofreiter, M. and Barnes, I. 2005

Assessing ancient DNA studies, Trends in Ecology and Evolution 20: 541-544.

Gutsmiedl-Schümann, D. 2005

Die justinianische Pest nördlich der Alpen? Zum Doppelgrab 166/167 aus dem frühmittelalterlichen Reihengräberfeld von Aschheim Bajuwaring, B. Päffgen, E. Pohl und M. Schauder (eds.), Cum grano salis. Beiträge zur europäischen Vorund Frühgeschichte. Festschrift für Volker Bierbrauer zum 65. Geburtstag. Friedberg: Likias, 199-208.

\section{Gutsmiedl-Schümann, D. 2010}

Das frühmittelalterliche Gräberfeld AschheimBajuwarenring. Materialhefte zur bayerischen Vorgeschichte, A95, Oberpfalz: Kallmünz.

Haensch, S., Bianucci, R., Signoli, M., Rajerison, M., Schultz, M., Kacki, S., Vermunt, M., Weston, D.A., Hurst, D., Achtman, M., Carniel, E. and Bramanti, B. 2010

Distinct clones of Yersinia pestis caused the Black Death. PLoS Pathogens 6 (10): e1001134.

Hofreiter, M., Jaenicke, V., Serre D., von Haeseler, A. and Pääbo, S. 2001

DNA sequences from multiple amplifications reveal artifacts induced by cytosine deamination in ancient DNA, Nucleic Acids Research 29: 47934799.
Kacki S., Rahalison L., Rajerison M., Ferroglio E. and Bianucci R. 2011

Black Death in the rural cemetery of Saint-Laurent -de-la-Cabrerisse Aude-Languedoc, southern France, 14th century: immunological evidence, Journal of Archaeological Science 38: 581-587.

Kolman, C.J., Centurion-Lara, A., Lukehart, S.A., Owsley, D.W. and Tuross, N. 1999

Identification of Treponema pallidum subspecies pallidum in a 200-year-old skeletal specimen, The Journal of Infectious Diseases 180: 2060-2063.

Little, K.L. 2007

Life and afterlife of the first plague pandemic, in: Plague and the End of Antiquity. The Pandemic of 541-750, K. L. Little, (ed.), Cambridge: Cambridge University Press, 1-32.

\section{Maddicott, J. 2007}

Plague in Seventh-Century England, in: Plague and the End of Antiquity. The Pandemic of 541750, K.L. Little, (ed.), Cambridge: Cambridge University Press, 171-214.

Morelli, G., Song, Y., Mazzoni, C.J., Eppinger, M., Roumagnac, P., Wagner, D.M., Feldkamp, M., Kusecek, B., Vogler, A.J., Li, Y., Cui, Y., Thomson, N.R., Jombart, T., Leblois, R., Lichtner, P., Rahalison, L., Petersen, J.M., Balloux, F., Keim, P., Wirth, T., Ravel, J., Yang, R., Carniel, E. and Achtman, M. 2010

Yersinia pestis genome sequencing identifies patterns of global phylogenetic diversity. Nature Genetics 42 (12): 1140-1143.

Papagrigorakis, M.J., Yapijakis, C., Synodinos, P.N. and Baziotopoulou-Valavani, E. 2006 DNA examination of ancient dental pulp incriminates typhoid fever as a probable cause of the Plague of Athens, International Journal of Infectious Diseases 10: 206-214. 
Parkhill, J., Wren, B.W., Thomson, N.R., Titball, R.W., Holden, M.T., Prentice, M.B., Sebaihia, M., James, K.D., Churcher, C., Mungall, K.L., Baker, S., Basham, D., Bentley, S.D., Brooks, K., Cerdeno-Tarraga, A.M., Chillingworth, T., Cronin, A., Davies, R.M., Dougan, D.P., Feltwell, T., Hamlin, N., Holroyd, S., Jagels, K., Karlyshev, A.V., Leather, S., Moule, S., Oyston, P.C., Quail, M., Rutherford, K., Simmonds, M., Skelton, J., Stevens, K., Whitehead, S. and Barrel, B.G. 2001

Genome sequence of Yersinia pestis, the causative agent of plague, Nature 413: 523-527.

Poland, J.D. and Dennis, D.T. 1999

Diagnosis and Clinical Manifestations, in: $W H O$ Plague Manual, World Health Organization, Geneva, pp 43-54.

Pusch, C.M., Rahalison, L., Blin, N., Nicholson, G.J. and Czarnetzki, A. 2004

Yersinial F1 antigen and the cause of Black Death, Lancet Infectious Diseases 4: 484-485.

Raoult, D., Aboudharam, G., Crubezy, E., Larrouy, G., Ludes, B. and Drancourt, M. 2000

Molecular identification by "suicide PCR" of Yersinia pestis as the agent of medieval Black Death, Proceedings of the National Academy of Sciences of the United States of America 97: 12800-12803.

Reimann, D., Düwel, K. and Bartel, A. 2000

Vereint in den Tod - Doppelgrab 166/167 aus Aschheim, in Das archäologische Jahr in Bayern 1999. Bayerisches Landesamt für Denkmalpflege und Gesellschaft für Archäologie in Bayern (ed). Stuttgart: Konrad Theiss, 83-85.

Retief, F.P. and Cilliers, L. 1998

The Epidemics of Athen, 430-426 BC, South African Medical Journal 88: 50-53.
Retief, F.P. and Cilliers, L. 2000

Epidemics of the Roman Empire, $27 \mathrm{BC}$ - AD 476, South African Medical Journal 90: 267-272.

Roberts, C. and Ingham, S. 2008

Using ancient DNA analysis in palaeopathology: A critical analysis of published papers, with recommendations for future work, International Journal of Osteoarchaeology 18: 600-613.

\section{Sallares, R. and Gomzi, S. 2001}

Biomolecular archaeology of malaria, Ancient Biomolecules 3: 195-213.

Sarris, P. 2002

The Justinianic plague: Origins and effects, Continuity and Change 17: 169-182.

Schuenemann, V.J., Bos, K., DeWitte, S., Schmedes, S., Jamieson, J., Mittnik, A., Forrest, S., Coombes, B.K., Wood, J.W., Earn, D.J.D, White, W., Krause, J. and Poinar, H.N. 2011

Targeted enrichment of ancient pathogens yielding the pPCP1 plasmid of Yersinia pestis from victims of the Black Death. Proceedings of the National Academy of Sciences of the United States of America Early Edition, doi 10.1073/pnas.1105107108

Staskiewicz, A. 2007

The early medieval cemetery at Aschheim-Bajuwarenring - a Merovingian population under the influence of pestilence?, in: Documenta Archaeobiologiae 5. Skeletal series and their socioeconomic context, G.. Grupe and J. Peters, (eds.), Rahden: Leidorf, 35-56.

Stenseth, N. C., Atshabar, B.B., Begon, M., Belmain, S.R., Bertherat, E., Carniel, E., Gage, K.L., Leirs, H. and Rahalison, L. 2008

Plague: Past, present, and future, PloS Medicine 5: e3, 0009-0013. 
Stone, A.C., Wilbur, A.K., Buikstra, J.E. and Roberts, C.A. 2009

Tuberculosis and leprosy in perspective, Yearbook of Physical Anthropology 52: 66-94.

Tran, T-N-N., Signoli, M., Fozzati, L., Aboudharam, G., Raoult, D. and Drancourt, M. 2011

High throughput, multiplexed pathogen detection authenticates plague waves in medieval Venice, Italy, PLoS One 6: e16735.

Twigg, G. 1984

The Black Death: A biological reappraisal, London: Batsford.

\section{van Oven, M. and Kayser, M. 2009}

Updated comprehensive phylogenetic tree of global human mitochondrial DNA variation, $\mathrm{Hu}$ man Mutation 30: E386-E394. http://www.phylotree.org.

\section{Vasold, M. 2003}

Die Pest: Ende eines Mythos, Stuttgart: Theiss.

Vasold, M. 2008

Grippe, Pest und Cholera. Eine Geschichte der Seuchen in Europa, Stuttgart: Franz Steiner Verlag.

\section{Wiechmann, I. and Grupe, G. 2005}

Detection of Yersinia pestis DNA in two early medieval skeletal finds from Aschheim (Upper Bavaria, 6th century A.D.), American Journal of Physical Anthropology 126: 48-55.

Wiechmann, I., Harbeck, M. \& Grupe, G. 2010 Yersinia pestis DNA sequences in late medieval skeletal finds, Bavaria, Emerging Infectious Diseases 16: 1806-1807.

\section{Wilderotter, H. 1995}

Alle dachten das Ende der Welt sei gekommen. Vierhundert Jahre Pest in Europa, in: Das große Sterben. Seuchen machen Geschichte, H. Wilderotter (ed.), Dresden: Jovis, 12-53.

\section{Willerslev, E. and Cooper, A. 2005}

Ancient DNA, Proceedings of the Royal Society B 272: 3-16

Yang, D.Y., Eng, B., Waye, J.S., Dudar, J.C. and Saunders, S.R. 1998

Technical note: Improved DNA extraction from ancient bones using silica-based spin columns, American Journal of Physical Anthropology 105: 539-543.

\section{Yersin, A. 1894}

La peste bubonique à Hong Kong, Annales de l'Institut Pasteur 8: 662-667. 


\section{REZIME}

MOLEKULARNO-GENETSKO OTKRIVANJE UZROČNIKA BOLESTI NA ARHEOLOŠKOM SKELETNOM MATERIJALU NA PRIMERU YERSINIA PESTIS

KLJUČNE REČI: KUGA, YERSINIA PESTIS, STARA DNK, MOLEKUlaRNA PALEOPATOLOGIJA, PALEOMIKROBIOLOGIJA, CRNA SMRT.

Epidemije prouzrokovane infektivnim bolestima često su oblikovale istoriju čovečanstva. Na osnovu ne baš preciznih opisa bolesti iz istorijskih izvora teško je odrediti koja je tačno bolest prouzrokovala dalekosežne posledice. Razvila se čak i kontroverzna rasprava da li se u slučajevima srednjevekovne kuge, tzv. crne smrti, i justinijanske kuge tokom kasne antike i ranog srednjeg veka, zaista radilo o kugi. Kugu prouzrokuje bakterija Yersinia pestis, koju prenose buve, a čiji su pravi domaćini zapravo glodari. Epidemija kuge nastaje kada nosilac kuge dospe u populaciju pacova. Zaražene pacovske buve nakon smrti svog prvobitnog domaćina - pacova - u velikom broju prelaze na ljude. Sumnja da je Y. pestis uzročnik crne smrti i justinijanske kuge obrazlaže se razlikama u epidemiološkim manifestacijama ovih istorijskih pandemija u poređenju sa poslednjom pandemijom kuge u 19. veku. Jedan od pristupa ovom problemu je analiza DNK uzoraka uzetih sa pretpostavljenih žrtava kuge iz pomenutih istorijskih perioda. Naime, DNK bakterije koja je u trenutku smrti mogla biti sačuvana u krvotoku pokojnika, baš kao i DNK samog pokojnika, može ostati sačuvana u skeletnim ostacima žrtve.

U ovoj studiji su ispitivani ostaci potencijalnih žrtava kuge iz ranosrednjevekovnog groba (Ašhajm-Bajuvarenring, Bavarska, Nemačka) i iz srednjevekovnog masovnog groba (ManhingPihl, Bavarska, Nemačka). U te svrhe je iz pojedinih zuba individua uzet DNK uzorak. Delovi $Y$. pestis specifičnog plazmida $\mathrm{pPCP} 1$ su polimerskom lančanom reakcijom amplificirani, a zatim je niz upoređen sa DNK nizovima savremene $Y$. pestis.

Kod individua sa oba lokaliteta su se $Y$. pestis- specifični DNK fragmenti u velikoj meri podudarali sa savremenim nizovima patogena. Nekoliko uočenih neslaganja se mogu tumačiti kao proizvodi degradacije. Procenat uspešnosti od $10 \%$ podudara se sa onim iz drugih studija starih DNK. Osim toga, treba imati u vidu da negativan rezultat ne isključuje infekciju putem $Y$. pestis, već se može objasniti nedovoljnim obimom DNK uzorka.

Kod obe sahranjene individue potvrđena je pretpostavka da se radi o žrtvama justinijanske kuge, odnosno crne smrti. Zajedno sa malobrojnim preostalim dokazima prisutnim na skeletnom materijalu, a vezanim za $Y$. pestis, ovo predstavlja jasan o dokaz da je kuga zaista bila ta koja je i tokom ranog i punog srednjeg veka odnela toliko žrtava. Protivrečnosti u epidemiološkim pojavama istorijskih pandemija i pandemija 19. veka mogu se objasniti kompleksnom ekologijom začetnika oboljenja. Ispitivanja pojava kuge u savremenom dobu takođe pokazuju da postoji više mehanizama prenošenja nego što je to pretpostavljeno u okviru klasičnog modela prenošenja. Zato odstupanja u epidemiološkom toku ne moraju po svaku cenu da znače da se ne radi o kugi kao uzročniku istorijskih pandemija. Dokaz o kugi u ranosrednjevekovnoj sahrani iz Ašhajma (Aschheim) je za sada jedini postojeći dokaz da je justinijanska kuga prodrla u oblasti severno od Alpa. Molekularno-genetska istraživanja skeletnog materijala na nosiocima infekcije na taj način mogu da doprinesu određivanju uzročnika smrti pojedinaca. Ona ne samo da mogu da dokumentuju pojavu epidemija u određenoj populaciji, već i da odrede njihov uzrok i rasprostranjenost. Ipak, veliki broj pitanja koja se odnose na istorijske pandemije ostaje i dalje otvoren. Tako, na primer, do danas nisu razjašnjeni uzroci pojave kuge u antici, rasprostranjenost justinijanske kuge nije poznata do detalja, a geografsko poreklo kuge se još 
uvek samo pretpostavlja. Upravo tu mogu biti od izuzetnog značaja molekularno-genetske analize na pogodnom skeletnom materijalu iz određenih vremenskih perioda. 